\title{
Autonomy in English Learning and Academic Success: a Case Study
}

\author{
Huijuan XUE \\ Humanities and Management \\ Jiangxi Police Institute \\ Nanchang, China \\ Xuehuijuan1@yahoo.com
}

\begin{abstract}
This paper analyses how Qian utilises English learning strategies and improves learning efficiency to achieve academic success through autonomous learning based on a case study. The purpose of this study is to understand the correlation between her motivation, strategy, autonomous learning and academic performance to provide implications for English learners. It concludes that interest in English and motivation affect the choice of language learning strategies and effective strategies contribute to academic success.
\end{abstract}

Keywords-Learning interest; Motivation; English learning strategy; Academic success

\section{INTRODUCTION}

Learning motivation affects the choice of language learning strategies, and the choice of learning strategies affects learning efficiency and academic success. The new era has witnessed tremendous changes in language teaching, shifting from teacher- to student-centeredness. In 'the Internet + ' and the information age, it has become a norm to practice MOOC or micro-class and flipped classroom or integrate multi-media in a computer-aided teaching environment. Against such a background, this paper is based on the empirical data from a case study and scrutinises how the subject utilises English learning strategies, particularly how she improves learning efficiency and achieves academic success through autonomous learning. Such a study aims at understanding the correlation between her learning motivation, strategy, autonomous learning and academic success, thus providing implication for English language learners.

\section{LITERATURE REVIEW: LEARNING MOTIVATION, STRATEGY AND AUTONOMOUS LEARNING}

Interest in learning is the best teacher. Interest motivates one to do what she likes until she reaches her goal. There are many definitions for motivation. According to Keller, motivation means learners' choice for realizing their goals or purposes with efforts, which controls their behaviours and actions [1]. To put it in a simple way, language learning motivation is a driving force to motivate and inspire English learners in learning. It is a kind of internal psychological dynamism to propel English learners to achieve specific goals. Just as the definition of learning motivation varies, learning strategy is also defined differently. Learning strategy is the skills or techniques a learner uses in order to achieve a particular purpose, and it is a kind of specific action or behavioural pattern [2]. Learning strategies are the ideas or behaviours that learners employ to gain more profound information and finally to achieve an effective learning [3]. Li's study revealed that teaching learning strategies in college English not only improved students' learning outcomes but also contributed to forming good learning methods [4]. According to Feng, motivation has significant correlation with strategies [5]. Zhang investigates the relationship of foreign language learning motivation and strategy use by Chinese high school students and reveals that there exists a positive correlation between the frequency of utilization in strategy and intensity of learning motivation [6].

The key to learning strategy is to develop autonomy in learners. Autonomous learning, also called independent learning, means 'self-regulated learning'. In other words, it is the process of learners' understanding their learning, being motivated to take responsibilities for their learning. Little argues that learner autonomy and the growth of target language proficiency are mutually supporting and fully integrated with each other [7]. The empirical study with English majors by Xue illustrates that a good mastery of learning methods and strategies are crucial to fostering learning abilities and achieving academic success [8]. This study uses past research as a theoretical underpinning, analyses Qian's learning English strategies to understand the correlation between English learners' motivation, strategy, autonomous learning and academic performance to provide implications for English learners. It concludes that interest in English learning and motivations affect the choice of learning strategies and effective strategies contribute to academic success.

\section{RESEARCH METHOD AND SUbJECT}

This research adopts the qualitative method of in-depth interview. Because the study aims at understanding how Qian effectively utilises learning strategies, particularly how she improves learning efficiency and achieves academic success through autonomous learning, such a method fits the purpose. Through interview Qian's real 'voice' can be heard concerning her effective learning strategies to improve her English language proficiency. The semi-structured in-depth interview covers 26 questions in four aspects: 1. learning background, 2. learning interest and skills in listening, speaking, reading, writing, translation and vocabulary, 3. learning motivation and autonomous learning, and 4. learning method and strategy. The interview with Qian was conducted when the first term 
approached an end. At that time, she had got an unconditional offer from an Australian university (she is currently studying in Australia). Qian took IELTS immediately after the military training at the beginning of the new term in a police institute. After she got an UC she went home to prepare the oral test. During this period, the author outlined the interview questions while awaiting her back at the institute. It was a pity that she did not return, therefore the author contacted Qian via QQ and confirmed for an interview to research on autonomous learning and academic success. In December 2016, the semi-structured in-depth interview with Qian was conducted via QQ video, which lasted 1 hour and 35 minutes. The interview was transcribed verbatim immediately afterwards. Some impressive parts the author made special notes of during the interview and some unclear details like going-abroad were clarified and added via QQ shortly afterwards.

Qian, the subject of this study, is a freshman in a police institute. She was recruited with 134 in an English test at the entrance examination (including 120 for written and 14 for spoken test vs. the total being 135 for written and 15 for spoken test). According to Qian, much importance is attached to listening and speaking in Guangzhou where she is from, hence her good results in spoken English. In her view, the entrance examination truly reflected her English language proficiency, except for being a little lower than it should be. She informed that she was in the top 50 when taking simulated tests in the high school, with better results. Her total IELTS score was 6.5, including 7 for reading and listening respectively, 6 for both speaking and writing. Because the first month was for military training, Qian had been in the institute for a little over 3 months at the interview.

\section{CASE STUdy: AutonOMOUS ENGLISH LEARNING AND ACADEMIC SUCCESS}

\section{A. Cultivate Interest in Learning English and Develop Language Skills}

Qian was born in Guangzhou, China. Although both primary and junior middle-schools were ordinary ones with no foreign teachers, she actually started learning English with American teachers in 'interest classes' since kindergarten. In her opinion, because she was young, such additional learning of English did not exert much influence on her. The senior middle-school she went to was a municipal girls' school where her English spoken class was taught by an American teacher, twice a week and 80 minute each time. Reasonably speaking, such short hours of native-speaker's teaching did not really enable her to practice English much. However, statistics show that Qian's subsequent learning performance, outcomes and academic success are all attributed to her interest in learning English which was cultivated at a young age.

When interviewed, Qian recalled that her English was not very good in primary school and occasionally she had to stay behind to redo exercises. Still, compared with maths, her English and Chinese were better then and in high school she was only good at English. In her view, her English had a big leap forward in senior middle-school. Thus it can be seen that Qian's keen interest in English has never wavered all these years. In Qian's analysis, her interest in English had a lot to do with the fact that she liked to express herself. She would murmur in English fluently when excited. She considered herself to have a feel for languages. All through the interview, Qian attached great importance to learning interest. She articulated clearly that to study English well learners should have interest, motivation and a sense of achievement.

Statistics show that Qian likes English for 3 reasons: 1) English is 'elegant and trendy', 2) she wants to go to the USA and the UK because they are powerful but English is the mother tongue, and 3) she likes English 'Talk Shows' in which the British and American cultures attracted her passionately. She also commented that she liked British and American dramas most among those from America, Britain, Korea and Japan. She said intellectuals and white-collars in cosmopolitan cities like Guangzhou like watching American and British dramas and she wants to be one of them.

Regarding English language skills, Qian likes 'speaking' most and dislikes 'translation' (with no training in the latter area). Because she wanted to take international education abroad, Qian thinks that her weakness in translation did not really impact on her chances. When asked to evaluate the importance of 'listening', 'speaking', 'reading', 'writing', 'translation' and 'vocabulary' at the interview, Qian believed 'speaking' to be most important, trusting 'writing', and 'translation' in particular the least important. She thought 'translation' has to do with the Chinese language, and too much emphasis would not help English learning. In fact, Qian showed obvious differences in diverse English language skills, with 'speaking' as the strongest and 'writing' and 'translation' the weakest. Her spoken English was not as high as expected in IELTS due to her lack of experience. Even in the intensive class by the author, Qian showed her outstanding expressive abilities and fluency in speaking whereas she made simple grammar mistakes in 100-words writings.

\section{B. Practice Effective Learning Strategy and Strive for Academic Success}

Past research has shown that a good mastery of learning methods and strategies are crucial to enhancing learning abilities and achieving academic success [8]. This case study illustrates that constantly practising learning English by taking advantage of all opportunities available is Qian's most effective strategy to improve the language proficiency. In high school, she dare talk to native-speakers; although with mistakes she had a sense of achievement. She participated in the national English speech contest as a high school student and ranked No. 16 in the Guangzhou completion area. At that time, an American teacher organised the competition and supervised the students in school and she acknowledged having benefited a lot from it.

Qian owed her great progress in English language to the English Association she established in high school, with around 50 students attending. To organise activities in English, she, as a chair, spent one month preparing to speak for about half an hour. At interview, Qian informed that she utilised all sorts of learning methods and strategies to improve her language proficiency, covering reading English classics in original, watching English 'Talk Shows' and American dramas 
(eg. 'Friends' and 'Modern Family'), giving PPT presentations, talking to native-speakers, participating in English speech contests and organising English activities through the association. When watching American dramas she not only learned English expressions but also gestures and facial expressions which she considered equally important. All these learning strategies cumulatively pushed her English language proficiency to a new level.

Qian takes advantage of all opportunities to learn English. In high school, she went to Hong Kong for over 10 days on an exchange programme, during which period she was taught in English. She also had the opportunity to go to Beijing and learned English during one winter camp. Before she graduated from senior middle-school, she went to the education exhibition organised by USA and France. There she insisted on inquiring and exchanging information in English to improve the language proficiency, even though the Frenchman had a strong accent. The most impressive thing is Qian made a pen pal to practice writing English via email in the final year of high school, which lasted over a year. She summarised three advantages in doing so as below: 1) it improved her writing skills, 2) she learned some American culture and the pen pal's life, and 3) she felt extremely happy and became very confident. When asked to mark herself on the Likert 5-points scale, Qian gave ' 4.5 ' to her autonomous leaning. She believed that independent learning and academic success were closely correlated.

The other point worth mentioning is vocabulary learning in Qian's high school: consulting dictionaries. Her English teacher would assign a task for students to check the meanings of new words in dictionaries, over 10 words one time. Such a task included searching for the meanings, finding useful examples, collocations, idioms and prefixes and suffices, and students were required to write them down in their exercisebooks. Qian remarked on this requirement, 'Consulting dictionaries was very useful. We not only learned new words but also learned ways of thinking through collocations, idiomatic expressions and sentence patterns and so on, which contributed greatly to our writing skills and reading comprehension.'

\section{CONCLUSION}

This paper discusses the correlation between learning interest, motivation, strategy and academic success based on a case study via a semi-structured in-depth interview. It shows that independent learning and effective strategies contribute significantly to academic success. Three points emerge important as below.

(1) Interest in learning is the best teacher. This case study reveals that Qian has a great interest in learning English well. She has a strong motivation to learn it well because she thinks it is a trendy thing to speak good English, watch British and American dramas and have a stylish life. In this light, it is advisable that learners develop a keen interest in English and motivate themselves to work hard for it. In the meantime, teachers should stimulate learners by enriching teaching materials from different sources and adopting inspiring teaching methods through integrating multi-media technology in class.

(2) Statistics shows that autonomous learning is the most effective strategy to enhance Qian's English level, through giving PPT presentations, participating national English speech contests, establishing and chairing the English association, even finding a pen pal to practise English writing. Against the back background of MOOC and blended-learning in the information age, learners have a large language resource bank available. Likewise, students should take an advantage of English original novels, English talk shows, British and American dramas, videos and tapes, English songs, attending English contests, dubbing English movies on social medium applications. Learning English via consulting dictionaries is a traditional yet not outdated way. It is universally acknowledged that memorisation in second-language acquisition is indispensable. A key to motivate is to develop students into responsible and autonomous learners. Self-directed learners are not intellectual Robinson Crusoes, cast away and shut off in self-sufficiency. In this sense, the important role of teachers in enabling and supporting learners cannot be over-stressed in fostering learner autonomy.

(3) It is essential to practise English. Chinese students are usually weak in the productive skills of speaking and writing, but Qian's case proves one can speak English well so long as she dares to open her mouth to practise. Talking to nativespeakers is daunting at the beginning but once learners overcome the fear and override the psychological barrier, they will find great fun in the progress they are making. Adopting a pen pal is a good way to start with in developing written skills.

\section{REFERENCES}

[1] Keller, J. M. (1983) Motivational Design of Instruction. In C. M. Reigeluth (Ed.). Instructional Design Theories and Models: An Overview of their Current Status. Hillsdale, NJ: Erlbaum.

[2] Stern, H. (1983) Fundamental Concepts of Language Teaching. Oxford: Oxford University Press.

[3] O'Malley, J. \& Chamot, A. (1990) Learning Strategies in Second Language Acquisition. Cambridge University Press.

[4] Li, Y. (2008) 'Practise Teaching English Learning Strategy in College English Environment', Foreign Language World, 4: 82-87.

[5] Feng, C. A. (2010) 'Correlational Study of Language Learning Motivation and Strategies of Chinese Undergraduate', Canadian Social Science, 6 (4): 202-209.

[6] Zhang W. (1998) 'The Relationship between Motives and Strategy Use of Foreign Language Learning', Foreign Language and Foreign Language Teaching, 3: 25-27.

[7] Little, D. (2007) 'Language Learner Autonomy: Some Fundamental Considerations Revisited', Innovation in Language Learning and Teaching, 1 (1): 14-29.

[8] Xue, H. 'On English Learning Strategy — an Empirical Study on the English Majors at Jiangxi Police Institute', Journal of Jiangxi Police Institute, Forthcoming. 